\title{
What is deflationism about truth?
}

\author{
Matti Eklund $^{1}(\mathbb{D}$
}

Received: 24 March 2016 / Accepted: 6 September 2017 / Published online: 20 September 2017

(C) The Author(s) 2017

\begin{abstract}
What is deflationism about truth? There are many questions that can be raised about this, given the numerous different characterizations of deflationism in the literature. Here I attend to questions about the characterization of deflationism that arise when we carefully distinguish between issues pertaining to concepts and issues pertaining to properties.
\end{abstract}

Keywords Truth · Deflationism · Concepts · Properties · Rejectionism · Indeterminism · Michael Lynch · Nic Damnjanovic · Jeremy Wyatt

\section{Introduction}

In this paper I will be concerned with a certain cluster of questions regarding how best to understand deflationism about truth.

First some relevant background. Deflationism about truth is a kind of reaction to classical theories of truth. Among classical theories of truth are the correspondence theory, according to which truth is correspondence with reality, the coherence theory, according to which truth somehow consists in coherence, and pragmatist and verifi-

Many thanks to Jeremy Wyatt and to two anonymous referees for helpful comments on earlier versions. Thanks also to audiences at the University of Tampere and Umeå University for helpful feedback.

$\bowtie \quad$ Matti Eklund

matti.eklund@filosofi.uu.se

1 Uppsala University, Uppsala, Sweden 
cationist theories according to which truth somehow consists in ideal verifiability. ${ }^{1}$ These theories are all naturally seen as attempting to uncover the nature of truth: and the deflationist retort is that truth has no nature of this kind to uncover.

Sometimes deflationism has been undergirded by a general anti-metaphysical stance. In the Stanford Encyclopedia of Philosophy entry on deflationism (2010), Daniel Stoljar and Nic Damnjanovic remark that "One reason for the popularity of deflationism is its anti-metaphysical stance. Deflationism seems to deflate a grand metaphysical puzzle, a puzzle about the nature of truth, and much of modern philosophy is marked by a profound scepticism of metaphysics". Not all deflationists are animated by a general disdain for metaphysics, especially not today, after metaphysics has had a renaissance. Even the ones that are not think that because of something about truth, certain traditional metaphysical questions do not arise in the case of truth. If truth has no nature to uncover, there is no metaphysical project of uncovering the nature of truth.

More specifically, deflationists typically make the following three kinds of claims:

(i) Exhaustion What truth is, is exhausted by some schema like

(ES) (The proposition) that $\mathrm{p}$ is true iff $\mathrm{p}$

or

(DS) "p" is true iff $p$,

or perhaps some suitably universally quantified version thereof. ("ES" for Equivalence Schema and "DS" for Disquotation Schema. "True" as used in (ES) applies to propositions; "true" as used in (DS) applies to sentences.) Much of the discussion of deflationism is concerned with the exact formulation and status of these schemata, or the corresponding variants. What are the appropriate instances? What is the modal status? What about the language-relativization that would appear to be needed in the case of (DS)? Also in the case of (DS), how does one deal with different forms of context-sensitivity? If one operates instead with a universally quantified version, how should one understand the kind of quantification at issue? Does the deflationist's characterization of truth offer everything that one can reasonably expect from a characterization of truth, for example for logical purposes? Even though I will be centrally concerned with how exactly to understand deflationism, I will not be at all concerned with the issues just mentioned. I will sweep all this under the rug, simply assuming that the issues just brought up all can be resolved in some satisfactory way. I will speak of the deflationist as thinking that truth is characterized by "the relevant schema", but that should not be understood as my taking a stand on whether a schema or some quantified formulation is best.

In recent years it has become more common to speak of inference rules somehow governing truth. The deflationist might appeal to the rules from it is true that $p$ to: $p$ and from $p$ to: it is true that $p$, and say that truth is somehow exhausted by those rules. I do not mean to beg the question against a rule-based characterization

1 For a helpful overview of theories of truth, see Glanzberg (2013). 
although my formulations will concern schema-based ones. The points I make will carry over. (As I will remark on, the problem I will be centrally concerned with is more serious for rule-based approaches.)

Other questions regarding the proper formulation of deflationism about truth concern whether the deflationist can consistently with her overall outlook take truth to be defined in terms of reference and satisfaction, à la Tarski, appealing to deflationary theories of reference and satisfaction in turn. A deflationary thesis about reference analogous to the schema-based characterization of truth would be that a schema like

' $t$ ' refers to $t$ if $t$ exists, and to nothing otherwise in some sense exhausts the nature of reference. ${ }^{2}$

(ii) Expressive device A second claim is that truth is just an expressive device, of use for mimicking infinite disjunctions and conjunctions, and for saying things like "Everything the pope says is true" (said by someone who trusts the infallibility of the pope but does not know exactly what the pope has ever said), but without any deeper explanatory use. Sometimes - in connection with truth predicates of sentences-it is said that truth is a device for disquotation. Again some good questions can be asked, for example about what constitutes explanatory uses of the truth predicate. Again that will not be my topic.

(iii) No genuine property Truth is a not a property — or, more cautiously, truth is not a genuine property, or truth is not a substantive property, or truth is just a property in a "logical" sense. It does not have a "nature" of the kind that other, ordinary properties have. This again stands in some need of clarification, for example because qualifiers like "genuine" and "substantive" as used in the context are not fully clear, and because "property" is used differently by different theorists. Let me first pause on the latter issue. Some theorists use "property" in such a way that they hold that all expressions that semantically function like predicates "ascribe properties". If such a theorist says "truth is not a property", she conveys that the truth predicate (or perhaps so-called truth predicate) does not function semantically like a predicate. Some deflationists - prominently prosententialists - have made this sort of claim. ${ }^{3}$ It is an interesting claim, but evaluating it is beyond the scope of this article. I will restrict attention to forms of deflationism which are moderate in that they do not deny that the truth predicate functions semantically as a predicate. Other theorists use "property" in such a way that there only are "properties" corresponding to predicates that, as it is often put, carve nature at its joints. If a theorist says that "true" does not ascribe a property in this sense, then while what she says is no doubt of some significance, she only claims about the truth predicate what goes for many predicates, of different kinds. It is not a very distinctive claim. ${ }^{4}$ As for "genuine", "substantive" etc., these are somewhat unclear bits of jargon. Some authors-for example Damnjanovic (2010),

\footnotetext{
2 See e.g. Båve (2009), Field (1994), Horwich (1998, ch. 5), Leeds (1978) and McGee (1993, 2016) on deflationism about reference.

3 On prosententialism, see primarily Grover (1992).

4 Burgess and Burgess (2011, p. 47f), also complain, and along similar lines, that slogans of this kind are not very helpful.
} 
Edwards (2013) and Wyatt (2016) - have recently done more than has previously been done to elucidate what these pieces of jargon mean. I will later in the discussion have occasion to bring up some suggestions they make.

Thesis (i) is the basic claim, as it is this thesis that constitutes a positive claim about what truth is. It is natural to see theses (ii) and (iii) —making claims about the uses of truth, and about what the property of truth is not, respectively - as carried in the wake of (i). If they do not actually follow from (i), they are at least supposed to be very well motivated given (i). If truth is exhausted by one of the schemata, it is just an expressive device. If truth is exhausted by one of the schemata, then truth is not a property — or at least not a substantive one. There are other respects in which theses like (ii) or (iii) might be more basic. They might speak more directly to the motivation behind deflationism. Or they might be more nearly definitional of what makes a view deflationary. But those are different matters.

My main focus will be thesis (i). I will discuss some basic questions regarding what this thesis means. Specifically, I will ask whether it is supposed to concern only the concept TRUTH or also the property of being true, argue that it must be the latter, and then make critical remarks regarding what (i), understood as concerning the property, might mean. Questions about whether the property of being true is a "substantive" property will not be my main focus, but issues in that vicinity will come up. One question I will be concerned with is whether (i) can serve as a characterization of the property of being true which serves deflationist purposes and rules out traditional views on truth. One question there is whether (i) can lend support to (iii), and then the interpretation of (iii) becomes relevant.

\section{Concepts and properties}

As indicated, what I will be centrally concerned with is the distinction between concepts and properties, and how attention to this distinction matters to the discussion of deflationism. Properties are had by their bearers; concepts represent. There can be different concepts of the same property. Even if the property of being water = the property of being $\mathrm{H}_{2} \mathrm{O}$, arguably the concept WATER $\neq$ the concept $\mathrm{H}_{2} \mathrm{O}$. To illustrate the concept/property distinction, compare a famous use of the concept/property distinction in metaethics. Moore (1903) apparently sought to establish something about the nature of the property of being good from the fact that for any analysis of the concept good, it is an open question whether something which satisfies the analysans is thereby good. This is the famous open question argument. The argument is also famously problematic. While this argument is often held to establish that the concept GOOD is not identical to any naturalistic concept, many theorists resist the further conclusion that the property of being good therefore cannot be identical with any naturalistic property, and Moore is criticized for not properly heeding the concept/property distinction.

Although I will for the most part be focusing on the distinction between concepts and properties, more generally the relevant distinction is between representational devices on the one hand - whether words or concepts-and properties on the other. I will sometimes talk about the predicate "true" instead of the concept TRUTH. 
Some may have philosophical objections to the distinction between properties and concepts. They may for example be skeptical that concepts, understood as described, are usefully postulated. I have two remarks on this sort of skepticism. First, much of what I say under the heading of the concept/property distinction can equally well be presented under the heading of the distinction between a word and the property it stands for. Second, what I will eventually be mainly concerned with is how deflationism about the property of being true is best construed. For many purposes, the discussion of concepts is there only as a foil, warning against a conflation between different things. If we should simply renounce concepts, so be it.

We can ask concerning any philosophical account of $\mathrm{X}$ whether it works (or is supposed to work) as an account of the concept X or as an account of the property X. This applies also in the case of truth. For example, one possibility is that the concept TRUTH is unanalyzable but one of the classical theories of truth is correct regarding the property of being true. The correspondence theory of truth can fail as an analysis of the concept TRUTH, but still provide a correct account of the property of being true. One can generally be skeptical of the project of providing conceptual analyses but be more optimistic about the corresponding project of giving a correct and informative account of the nature of some property. ${ }^{5}$

With the concept/property distinction on the table, return to (i). When stating (i) above, I was deliberately cagey. I said that on the deflationist view, (i) states "what truth is". But is a characterization along the lines of (i) best understood as an account of the concept TRUTH, the property truth, or both?

Note incidentally that the two other theses, (ii) and (iii), speak to different sorts of things. Someone who affirms thesis (ii), that truth is just an expressive device, must be speaking of a representational device - the truth predicate, or the concept TRUTH. It is representational devices that are the sort of thing that can be expressive devices. Properties are hardly the sort of thing that can be expressive devices. One can perhaps posit a property for the expressive gains that doing so offers, but that is different. Someone who affirms thesis (iii), that truth is not a genuine property, must mean that what the concept TRUTH stands for is not a genuine property. That the concept TRUTH is not a property is trivial.

Suppose first that (i) only purports to characterize the concept TRUTH. What this would mean is, I take it, something like that the concept TRUTH is exhausted by one of the schemata in the sense that it is necessary and sufficient for competence with the concept to be disposed to accept the instances of these schemata. ${ }^{6}$

There are complications here. Quine was a prominent deflationist, and many more recent deflationists are clearly inspired by Quine. And Quine very prominently and centrally disavowed claims about what is necessary and sufficient for competencethis is part and parcel of his attack on analyticity. So there are deflationists for whom

\footnotetext{
5 See the discussion in the early pages of Wright (1998). Someone may object to the suggestion in the text that any reasonable argument in favor of some theory of the property of being true would have to be a priori in character, and that any good a priori reasoning would have to be conceptual in character. But both assumptions relied upon are eminently questionable.

6 Or perhaps to be committed to so accepting them. The details regarding the account of competence do not matter for present purposes. The important point is that the exhaustion claim, understood as being about the concept, can be taken to be about what competence with the concept involves.
} 
there arise problems regarding how to understand (i) when the thesis is conceived of as concerning the concept TRUTH. But let me anyway for now set this aside. One may simply think: so much the worse for the coherence of the Quinean package of views.

If thesis (i) only concerns the concept, then thesis (i) is fully compatible with the correspondence theorist being right about the property of being true. ${ }^{7}$ This is not to say that (i) thus understood is uninteresting: but deflationism about the concept does not by itself have the metaphysical import that deflationism is often taken to have.

Suppose then that (i) (also) concerns the property. (Recall yet again that I am setting aside versions of deflationism which deny that truth grammatically is a predicate, as well as quibbles about which genuinepredicates stand for properties.) This raises a question: what does the exhaustion claim come to there? Since one cannot reasonably talk about competence with a property as opposed to competence with a concept, one cannot simply adapt what was suggested in the case of the exhaustion claim regarding the concept.

Early on I mentioned that some who defend deflationary theses in the style of (i) take what characterizes truth not to be the instances of some schema but instead to be corresponding rules of inference. But if the characterization of truth alluded to under (i) essentially appeals to rules of inference, it is hard to see how it could be the property that is characterized, since inference rules govern expressions and concepts, not properties. A property can certainly in some sense validate the rules, but that is different. What are governed by rules are not properties but representations thereof, and if one spoke of properties couching things in terms of rules would at best be misleading. So for the characterization to pertain to the property, it will have to be of a different kind, and in discussion of the property of being true that follows I will presume that it is.

Here is a first stab at what the characterization claim might come to:

(E1) (The instances of) the schema state all the facts about truth.

But claiming this would be silly. There will certainly be other facts about truth besides facts stated by (instances of) the schema. Second stab:

(E2) (The instances of) the schema state all the necessary facts about truth.

But there will certainly be other necessary facts besides facts stated by (instances of) the schema. For example, that it is necessarily true that $7+5=12$. If one focuses on (DS) rather than (ES) and conceives of the truth predicate as a predicate of sentences, it is somewhat more tricky to come up with counterexamples to (E2), for it is natural to think that it is not necessarily the case that " $7+5=12$ " is true-the sentence could have meant something else. But first, deflationists focusing on (DS) tend to take the instances of (DS) as necessary; and then, given that it is necessary that $7+5=12$, it will be necessary that " $7+5=12$ " is true. Second, even if the instances of (DS) are not taken as necessary, there are other necessary facts about truth in the vicinity, for example that it is necessarily the case that actually, " $7+5=12$ " is true.

A better suggestion is:

7 See here also Alston (1996). 
(E3) (The instances of) the schema state all the facts pertaining to the essence or nature of truth.

But (E3) too faces problems. First, if the deflationist's claim is (E3), what happened with the supposed anti-metaphysical stance? Positive claims about what is part of the essence or nature of what are part and parcel of hardcore metaphysics. (This first point only concerns the compatibility of reliance on (E3) with the anti-metaphysical stance that often goes together with deflationism. The friend of deflationism could in principle just respond by eschewing the anti-metaphysical stance.) Second, even if (E3) does yield a characterization of the property of being true incompatible with all the traditional inflationary views, the question remains of why what is characterized is a properly deflationary view given which truth is somehow not as much of a genuine property as other properties. Why isn't this an alternative form of inflationism? Truth too has a nature; it is just that its nature is different from what traditional theories of truth have taken it to be. How does the truth of (E3) lend support to (iii), on any reasonable interpretation of the latter thesis?

Apart from these problems, note that even given (E3), it could be that when something is true it corresponds with reality-and even that this is so as a matter of metaphysical necessity. (E3) is incompatible with a claim to the effect that truth's nature is correspondence, but that is another matter. Similar points hold for other inflationary theories. Of course, this need not bother the deflationist: she can still say that she disputes the inflationist claims about truth's nature. But so long as truth necessitates correspondence, all the familiar supposed problems regarding correspondence remain.

It may be tempting for the deflationist who is worried about the use of ideology like "essence" or "nature" to try to avoid the talk of essences or natures by appeal to how all the facts about the property of truth are explained by the instances of the relevant schema together with independent facts. The other problem regarding (E3) still remains, but it may still be useful to pause on this appeal to explanation. What does "explanation" mean here? One can distinguish two different ways of talking about explanation. On a pragmatic way of talking about explanations, explanations are simply answers to "why"-questions, and since interests and background knowledge can vary with context so does what is an acceptable explanation in this sense. Second, sometimes in philosophy a more metaphysical notion of explanation is employed, and what is considered is what genuinely explains what in the nature of things. I take it that the deflationist claim we are now considering would have to concern explanation in the second sense: it is about what truth is like in itself. But then while "explanation" is not as overtly steeped in metaphysics as "essence" and "nature" are, the brand of explanation we are dealing with here is metaphysical explanation. We're talking about what really, in the nature of things, constitutively depends on what. We're not using a pragmatically infused notion of explanation simply relating to "why"-questions whose import vary from context to context. Once it is emphasized that it is properly metaphysical explanation we are talking about, the talk of explanation in this context should seem no less hardcore metaphysical than talk of natures or essences. Moreover, the other problems with appeal to essences or natures remain. (Similar remarks apply to suggestions according to which the instances of the schema state the fundamental facts about truth.) 
It may be suggested that explanation means deductive explanation. I am not sure that there is a separate species of explanation deserving of the name deductive explanations. Not all deductions are explanatory. (Most obviously, deductions like A $\vdash$ A.) But maybe the appeal to explanation is a red herring in the suggestion anyway. Maybe the core idea is to appeal neither to the essence or nature of truth nor to the order of metaphysical explanation, but to say that (the instances of) the relevant schema exhaust the property of truth precisely in that all facts about truth can be deduced from them together with facts not involving truth-nothing more and nothing less. It is natural to want to object that this disguises the problem rather than solves it. Is it not surreptitiously assumed that these deduction relations track some metaphysical relation: why else accord this significance to them? However, suppose the friend of appeal to deduction insists that her talk of deduction is not disguised talk of natures: instead of embracing the nature ideology she simply talks about what can be deduced from what. Doing this she embraces the view that no collection of claims from which all facts about truth follow is privileged; all such collections of claims are on a par. Adopting this package of views, she does get around the first of the problems for (E3) that were mentioned. The second problem concerned why what was being proposed was not a form of inflationism. To this it can now be responded that where the inflationist talks about truth's nature, the form of deflationism we are now exploring eschews the nature talk in favor of merely talking about what can be deduced from what. Something like what has been suggested strikes me as more promising than any of the earlier suggestions. But the cost is that it (pardon the pun) deflates the import of appeal to a schema. The schema now provides nothing more than a starting point for deductions; it is not claimed to be in any other way especially fundamental or central to the property of being true. ${ }^{8}$

The above considerations conclude the main negative argument of the present paper. It is not sufficient for the deflationist to think of (i) as a thesis concerning the concept TRUTH: for thus conceived (i) is compatible with traditional views on the property of being true. She must then think of (i) as (also) characterizing the property. But there are serious problems regarding how to understand the claim that one of the deflationist's schemata fully characterizes the property, as opposed to the concept.

In the sections to follow, I will discuss some suggestions from the recent literature on how to explicate the claim that truth is not a "substantial" property. It may be thought that these suggestions also might help elucidate in what sense in which the property of truth is supposed to be exhausted by some schema. However, my conclusions will be negative.

\section{Transparency}

One discussion that is in some ways unusually careful about the issues I have sought to highlight regarding the concept/property distinction and its relevance for discussions of deflationism is Michael Lynch's (2009) discussion of these matters (though

\footnotetext{
8 Not that it should be surprising that this is where we end up. This is the expected consequence of consistently avoiding the ideology of nature or essence, or anything similar.
} 
Lynch is himself no deflationist). Lynch is explicit that the deflationist schema-based characterization of truth is a characterization of the concept, and he explicitly brings up the question of how this characterization of the concept relates to what to say about the property:

...deflationists share a metaphysical view: truth has no nature... [Contemporary deflationists] allow that the truth concept does express a property-in the sense that the concepts of existence of identity express either a property or a relation. Such properties, we might say, are metaphysically transparent or pleonastic properties. Metaphysically transparent properties have no underlying nature that isn't revealed in our grasp of the concept; grasping the relevant concept tells us the whole essence of the property. ${ }^{9}$

Note first that the transparency of the property is presented as something additional to the concept TRUTH's being fully characterized by the relevant schema. Wisely, Lynch does not claim the former to follow from the latter.

Lynch's notion of transparency might be thought helpful when it comes to some different issues relating to deflationism. It might be thought to help explicate what it means for the property of truth to fail to be substantive: the thought being that the substantive properties are exactly the non-transparent properties. The points I will go on to make show that this thought is mistaken. But the issue of what it means for truth not to be a substantive property is not my main topic. I am instead primarily concerned with the issue of how to make sense of (i), understood as being about the property of being true. I will return to this issue at the end of the discussion of transparency.

But what exactly is it for a property to be "metaphysically transparent"? ${ }^{10}$ Lynch seems to say

(MT1) A property $\mathrm{F}$ is transparent iff $\mathrm{F}$ has no nature that isn't revealed in our grasp of the concept.

But which concept is meant here? Lynch's statement seems to be elliptical for:

(MT2) A property F is transparent iff F has no nature that isn't revealed in our grasp of the concept of $F$.

But there is an immediate problem: there are different possible concepts ascribing the same property. So one can't really speak of the concept. How can this be remedied? Here is one suggestion:

(MT3) A property F is transparent iff F has no nature that isn't revealed in our grasp of every concept of $F$.

But the condition for transparency stated by (MT3) is so strong that even the friend of deflationism should find it implausible that the property of being true satisfies the condition. Even if the nature of the property of being true is as the deflationist says

\footnotetext{
9 Lynch (2009, p. 106f); my emphasis.

10 The discussion to follow parallels earlier discussions by Damnjanovic (2010), Edwards (2013), and Eklund (2012).
} 
it is (however exactly this is to be construed), can there not be some concept of the property that fails to fully reveal its nature ${ }^{11}$ Avoiding this one may turn to:

(MT4) A property F is transparent iff F has no nature that isn't revealed in our grasp of some concept of $F$.

But this condition is so weak that many properties (perhaps every property?) turns out to be transparent. For a given property, consider a concept of the property that fully spells out its nature-even if our ordinary concept of the property fails to do so. (Compare perhaps: given that the property of being water $=$ the property of being $\mathrm{H}_{2} \mathrm{O}$, one can say that while the concept WATER fails to reveal the nature of this property, the concept $\mathrm{H}_{2} \mathrm{O}$ manages to do so.)

Instead one may then propose:

(MT5) A property $\mathrm{F}$ is transparent iff $\mathrm{F}$ has no nature that isn't revealed in our grasp of the ordinary concept of $\mathrm{F}$.

The condition stated by (MT5) arguably avoids the problems afflicting (MT3) and (MT4), and it marks some sort of perhaps not uninteresting distinction between properties. But it does not directly mark a distinction between properties as they are in themselves, but only via the way we think and talk about them. Even if our ordinary concept TRUTH is fully revealing, the ordinary concept WATER is not-but that is in the first instance just a point about how we ordinarily conceptualize truth and water, respectively. While it may perhaps be suggested that the way we think and talk about properties is evidence of real distinctions between the properties themselves, that would need to be made out. ${ }^{12}$ Lynch attempts to say something about what (on the deflationist view) is distinctive about the nature of the property of being true but only via the relationship between the concept TRUTH and the property it ascribes.

Having discussed characterizations of transparency, let me now explicitly return to different purposes to which the notion of transparency may be put. First, it could, as mentioned, be suggested that a property is substantive iff it is non-transparent, and thus that the appeal to transparency elucidates what it means to call truth non-substantive. But if, as per (MT5), transparency does not characterize a property per se but only the relation between a property and the ordinary concept thereof, this does not work. Second, could appeal to transparency help with the problems we have encountered in

\footnotetext{
11 What about, e.g., the concept has that property which Paul Horwich made distinctive claims about in his 1990 book? Well, the example arguably does not work in that form: the italicized expression does not ascribe the property truth but the second-order property of having the property that Horwich made distinctive claims about. A more convincing example illustrating the point is this. Suppose one introduces "schmuth" simply as a predicate ascribing whichever property that Horwich made distinctive claims about. Then arguably the concept SCHMUTH stands for the property of truth but fails to fully reveal the nature of the property it stands for. The possession conditions of the concept SCHMUTH are different from those associated with the concept TRUTH.

12 It may incidentally be noted that (MT5) by itself is quite compatible with the correspondence theory. A correspondence theorist might well hold that the ordinary concept TRUTH is a correspondence concept, and grasping it puts one in a position to know that the property of being true is the property of corresponding with reality. She can then hold that truth's nature is correspondence, so truth has no nature that isn't revealed by the ordinary concept TRUTH. By (MT5) she then holds that the property of being true is transparent. (Thanks here to Panu Raatikainen.)
} 
making sense of the deflationist's thesis (i), understood as concerning the property of being true? It could be of help here even if by itself it does not help elucidate nonsubstantivity. It could be suggested that the ordinary concept TRUTH is amenable to a schema-based characterization and if moreover, the property is transparent in the sense of (MT5), the schema also characterizes the property. But it is not hard to see that we have failed to make any progress at all: we have not made any further progress on the question - to which (E1)-(E3) were failed answers - of what it is for (the instances of) the schema to fully characterize the property to begin with.

Damnjanovic (2010) holds that while, for reasons similar to those I have rehearsed, a transparency claim by itself does not suffice to characterize deflationism, a transparency claim together with the further claim that truth is a logical concept characterizes an interesting form of deflationism. The claim of Damnjanovic's deflationist is that the concept TRUTH is a logical concept, and that since this special kind of concept moreover fully reveals the property it ascribes, that property is of a special kind-it is a logical property. But first, one immediate worry is that this amounts to punting. What is it for some concept or property to be logical? Damnjanovic simply remarks that the distinction is intuitive, even if it is hard to give a precise characterization of it. ${ }^{13}$ But even if the distinction is intuitive and should be taken on board, concerns remain. On some characterizations of logic, logic is characterized by formality and lack of content. On others, what characterizes logic is simply its absolute generality. Only given the first kind of characterization of logic does saying that truth is logical go any way toward vindicating the claim that it is somehow insubstantial or lacking a nature. Second, Damnjanovic's suggestion arguably runs into the same problems as those discussed in the last section. He wants to draw a significant conclusion about the nature of the property of being true from the concept TRUTH being a logical concept together with a transparency claim. The claim is then apparently that whichever features of the concept TRUTH renders it logical are also features of the property. Relating this to a schema-based characterization of deflationism, suppose that the concept TRUTH qualifies as a logical concept because it is, say, exhausted by (ES). Then the property of being true is a logical property because it is exhausted by (ES). But the topic of the previous section concerned what the exhaustion claim comes to in the case of properties and the conclusions were negative.

Wyatt (2016) discusses what claims about the metaphysics of the property of being true those deflationists who take truth to be a property are committed to, and he suggests that there are two such claims. First,

(Unconstituted) There is a property truth, but it is insusceptible to an opaque constitution theory. ${ }^{14}$

Opacity is here non-transparency. But where other theorists have discussed whether the property truth is itself transparent, Wyatt argues that what is at issue is really the constitution theory for the property, where a constitution theory for a property is a

13 Damnjanovic (2010, p. 46).

14 Wyatt (2016, p. 371). 
theory stating in what the property's being instantiated by something consists. I will not get into the details of this argument. Second,

(Non-Explanatory) There is a property truth, but truth lacks explanatory power in that there are no facts that are explained by facts about truth's essence. ${ }^{15}$

It is actually unclear to me why Wyatt focuses on essence here. Why not instead say "...in that there are no facts that are explained by facts about what is true"? (NonExplanatory) might seem too weak, leaving open the possibility that facts about what is true are explanatory, saying only that truth's essence is explanatorily powerless. I will not press the point. Maybe Wyatt relies on some bridge principle given which facts about what is true are explanatory only if truth's essence is.

As Wyatt rightly stresses, (Unconstituted) and (Non-Explanatory) are independent. One can perfectly well affirm one without affirming the other.

I like the idea of focusing on (Non-Explanatory), and I will return to this in the concluding section. But clearly - and this is no criticism of Wyatt-(Non-Explanatory) is not in any way a claim about what truth is, but only a claim about what truth can and cannot do. (Unconstituted), while only giving an indirect and partial characterization of what truth is like, at least speaks to the question of what truth is.

Earlier complaints about appeals to transparency apply also to (Unconstituted). Wyatt says "A constitution theory for truth is transparent iff one who possesses the ordinary concept TRUTH is ipso facto in a position to know that its axioms are true solely on the basis of conceptual argumentation". ${ }^{16}$ This explicitly adverts to the ordinary concept TRUTH. Saying that the property truth has a transparent constitution theory is only to say something about the relation between the ordinary concept TRUTH and the property of being true. Again to stress, all sorts of properties (and their constitution theories) can be opaquely presented by some concepts and transparently presented by others. That some property is presented some way by the ordinary concept of the property says more about our conceptual scheme than anything else. ${ }^{17}$

\section{Explanatory role}

It is common to associate deflationism with the idea that truth lacks an explanatory role- this is for example part of the point of the slogan that truth is merely an expressive device. A number of different authors have tried to explicate the supposed insubstantiality of the property of truth in terms of its not having any explanatory role. In this last section I will discuss some deflationary views in this spirit, and how they relate to schema-based characterizations of the kind problematized here.

\footnotetext{
15 Wyatt (2016, p. 372).

16 Wyatt (2016, p. 371).

17 In his statement of (Unconstituted), Wyatt uses "insusceptible", suggesting that there is a modal element in the characterization. But given his characterization of what a constitution theory for truth is, and his tying transparency to the ordinary concept TRUTH, I don't see that his "insusceptible to an opaque constitution theory" cannot be replaced without loss by "does not have an opaque constitution theory".
} 
I have already mentioned Wyatt's appeal to (Non-Explanatory). Edwards (2013) and Asay $(2013$, ch. 4, 2014) appeal to the notion of there being natural, or, as I will say, elite, properties, and says that if one operates with a notion of eliteness that admits of degrees, deflationism's characteristic claim about the property of being true is that it is relatively non-elite, whereas deflationism's opponents claim that it is relatively elite. While being elite is not the same as being explanatory, explanatoriness is one central aspect of eliteness.

As against both proposals, which are similar in spirit, it can be pointed out that even paradigmatic non-deflationary theories, like the correspondence theory, are perfectly compatible with truth being non-explanatory and non-elite. To state the obvious, moreover, appeal to truth's lack of explanatory role does not even promise to help elucidate how a schema-based characterization can be thought to exhaust the property truth. And intuitively, non-explanatoriness does not have anything to do with insubstantiality. Insubstantiality is intuitively a matter of not having very much by way of nature. But something can be quite substantial in this sense, but still be quite useless. ${ }^{18}$ Of course, none of these points militates against a revisionary proposal regarding the debate about truth, according to which one should shift the focus from the question of whether truth is substantial — whatever that means exactly - to the question of to what extent truth is explanatory, or elite.

Louis deRosset (manuscript) proposes a metaphysics of truth that he thinks captures important deflationist motivations. According to this metaphysics of truth, individual truth facts of the form that $p$ is true are grounded in the corresponding facts $p$, and these truth facts do not themselves in turn ground or metaphysically explain anything else. This may be an attractive view, and one that indeed does capture important deflationist motivations. But the connection between this form of deflationism and a deflationism that accords pride of place to one of the schemata remains unclear; nor does deRosset claim anything else.

In other work-Eklund (2010) - I myself have distinguished between the deflationist's positive claim about truth, as in some sense being fully characterized by (DS) or (ES), and the negative claim that truth does not have any useful explanatory or theoretical role, but insofar as the truth predicate has a use at all it is as an expressive device. What I stressed there was that the negative claim could in principle be plausible even if the positive claim turns out to be problematic. Even if no characterization of truth of the supposedly thin kind that deflationists strive for is correct, that is by itself no obstacle to the negative claim. I introduced the label rejectionism for the negative claim alone. Of course, rejectionism does not promise to deliver everything deflationism delivers. The point is precisely to focus on the negative claim only.

A theory I would now like to bring up — and which I will call indeterminism-is a bit closer to deflationism in saying something about what truth is (as opposed to merely what it doesn't do). According to indeterminism, all that is determined regarding the truth predicate, and the concept TRUTH, is that their meaning/content is exhausted by the relevant schema, in the sense that competence with the predicate or concept consists in being disposed to accept all instances of the schema. This is just what was suggested

18 Think perhaps of what are often called "gerrymandered" properties, grue and its ilk. Their natures can be quite complex; still they are explanatorily pretty useless. 
when it was discussed above what it might mean for the schema to exhaust the concept. But when it comes to the property of being true, what the indeterminist goes on to say is that there are many different properties that all could be ascribed by the concept TRUTH for all that this characterization determines. The conditions associated with the concept do not uniquely pick out one property as being what the concept stands for. For example, the indeterminist might say that any property satisfying the relevant schema would do. The concept TRUTH is semantically indeterminate as between all these properties. None of these individual properties need be in any reasonable sense exhausted by the schema. But the schema captures everything that these different properties that the concept TRUTH is indeterminate between have in common. ${ }^{19}$

Indeterminism comes closer than rejectionism does to capturing what one would associate with deflationism. It accords pride of place to (ES) or (DS) in a way that rejectionism does not. (The flip side of this is that while rejectionism can be accepted by orthodox Quineans, indeterminism's claim about the concept TRUTH incorporates a view on content alien to Quine.) While indeterminism cannot strictly say that there is a property truth whose nature is thin or insubstantial, it can say that what the candidates for being the property that "true" ascribes have in common is something fairly meagre.

There are objections that can be raised against the indeterminist proposal. For example, can't there be properties that satisfy the relevant schema but aren't plausibly candidate referents of "true"? But these are general concerns about how the truth predicate can have its semantic value fully determined by the relevant schema, and do not arise only for indeterminism.

Let me close by briefly returning to deflationist theses (i)-(iii). Thesis (i) can be understood to be about the concept TRUTH or the property of being true. Thesis (iii) can amount to different things, for example depending on how the substantiveness talk is understood. There is also unclarity I haven't yet paused on in thesis (ii). One type of claim is simply that a truth predicate's theoretical usefulness is exhausted by its use as an expressive device. A more ambitious claim is that somehow, due to the kind of meaning it has, it is guaranteed already by the semantics of the truth predicate that it is so.

The only one of these deflationist theses that the rejectionist embraces is thesis (ii), in its less ambitious form. The indeterminist also adheres to thesis (i), understood as a

19 There are some structural similarities to truth pluralism. There are now different, sophisticated varieties of truth pluralism but let me here give a simple characterization, lacking all sophistication. [(For more sophistication see e.g. Lynch (2009) and the essays collected in Pedersen and Wright (2013).] According to this simple truth pluralism any predicate or property that meets certain general conditions qualifies as a truth predicate or truth property, and different predicates and properties are truth predicates and truth properties for different discourses. The structural similarites are the focus on satisfaction of general conditions [though truth pluralists add more than (DS) or (ES)], and the emphasis on a plurality of predicates and properties that in some sense can be seen as truth predicates and truth properties. But the indeterminist says that occurrences of "true" are semantically indeterminate as between different properties, whereas the pluralist needn't commit to any such indeterminacy claim and can hold that an occurrence of "true" in, say, physics discourse determinately ascribes one property whereas an occurrence of "true" in, say, moral discourse determinately ascribes another. Conversely, it is no part of indeterminism to say that what "true" ascribes depends on the discourse. (Sophisticated pluralists might say not that "true" ascribes different properties depending on the discourse, but that the functionalist property truth is realized by different properties. The differences with indeterminism remain, mutatis mutandis.) 
claim about the concept TRUTH as opposed to the property of being true. Rejectionism and indeterminism may be attractive for a would-be deflationist, and there is a clear intuitive sense in which they deflate truth, there is much in what (i)-(iii) say that they do not vindicate.

Open Access This article is distributed under the terms of the Creative Commons Attribution 4.0 International License (http://creativecommons.org/licenses/by/4.0/), which permits unrestricted use, distribution, and reproduction in any medium, provided you give appropriate credit to the original author(s) and the source, provide a link to the Creative Commons license, and indicate if changes were made.

\section{References}

Alston, W. (1996). A realist conception of truth. Ithaca, New York: Cornell University Press. Asay, J. (2013). The primitivist theory of truth. Cambridge: Cambridge University Press. Asay, J. (2014). Against truth. Erkenntnis, 79, 147-64.

Båve, A. (2009). A deflationary theory of reference. Synthese, 169, 51-73.

Burgess, A., \& Burgess, J. (2011). Truth. Princeton: Princeton University Press.

Damnjanovic, N. (2010). New wave deflationism. In Wright \& Pedersen (Eds.) (pp. 45-58).

deRosset, L. (manuscript). The metaphysical transparency of truth.

Edwards, D. (2013). Truth as a substantive property. Australasian Journal of Philosophy, 91, 279-94.

Eklund, M. (2010). Rejectionism about truth. In Wright \& Pedersen (Eds.) (pp. 30-44).

Eklund, M. (2012). Theories of truth. In G. Russell \& D. G. Fara (Eds.), Routledge companion to the philosophy of language (pp. 199-208). New York: Routledge.

Field, H. (1994). Deflationist views of meaning and content. Mind, 103, 249-84.

Glanzberg, M. (2013). Truth. In Zalta, E. (Ed.), Stanford encyclopedia of philosophy, http://plato.stanford. edu/entries/truth/.

Grover, D. (1992). A prosentential theory of truth. Princeton: Princeton University Press.

Horwich, P. (1998). Meaning. Oxford: Oxford University Press.

Leeds, S. (1978). Theories of truth and reference. Erkenntnis, 13, 111-129.

Lynch, M. (2009). Truth as one and many. Oxford: Oxford University Press.

McGee, V. (1993). A semantic conception of truth? Philosophical Topics, 21(2), 83-111.

McGee, V. (2016). Thought, thoughts, and deflationism. Philosophical Studies, 173, 3153-68.

Moore, G. E. (1903). Principia ethica. Cambridge: Cambridge University Press.

Pedersen, N. J. L. L., \& Wright, C. D. (Eds.). (2013). Truth and pluralism: Current debates. Oxford: Oxford University Press.

Stoljar, D., \& Damnjanovic, N. (2010). The deflationary theory of truth. In N. Z. Edward (Ed.), Stanford Encyclopedia of Philosophy, http://plato.stanford.edu/entries/truth-deflationary/.

Wright, C. (1998). Truth: A traditional debate reviewed. Canadian Journal of Philosophy, 28, 31-74.

Wright, C. D., \& Pedersen, N. J. L. L. (Eds.). (2010). New waves in truth. Basingstoke: Palgrave Macmillan. Wyatt, J. (2016). The many (yet few) faces of deflationism. Philosophical Quarterly, 66, 362-382. 